PACS: 05.45.-a

UDC: 538.9

\title{
Dynamics of coupled nonlinear systems
}

\author{
A.S.Kovalev ${ }^{1,2}$, Y.E.Prilepskii ${ }^{3}$, K.A.Gradjushko ${ }^{2}$ \\ 1. B.Verkin Institute for Low Temperature Physics and Engineering of the National Academy of Sciences of Ukraine, 47 \\ Nauky Ave., Kharkiv, 61103, Ukraine \\ 2. V. N. Karazin Kharkiv National University, sq. Svobody 4, Kharkiv 61077, Ukraine \\ 3. Triangle Birmingham University, Aston Triangle, Birmingham, B4 7ET, UK, \\ E-mail:kovalev@ilt.kharkov.ua
}

ORCID: 0000-0002-2465-3458

DOI:10.26565/2222-5617-2019-31-01

Two models were studied theoretically which describe the dynamics of two nonlinear elements with linear and nonlinear interaction between them. These models correspond to the commutators in nonlinear fiber optics and artificial lattices of magnetic nanodots or magnetic layers in quasi-two dimensional compounds. The models illustrate the common situation in the nonlinear systems with two degrees of freedom. Usually the absence of additional to the total energy integrals of motion leads to the appearance of a chaotic component of the dynamics. This chaotic behaviour masks the reqular part of the total dynamics. In the studied in the paper two integrable systems the chaotic component is absent and the reqular dynamics manifest itself per se. In the paper at first the dynamics of the systems was investigated qualitatively in the corresponding phase planes. Two integrals of motion correspond to the total energy $E$ and the number $N$ of elementary excitations in the system (photons and spin deviations). The phase analysis demonstrates the complicated its dynamics. The excitations of different types are classified in the plane of the integrals $(N, E)$. For the fix number of excitations $N$ in the domain of small $N$ the dynamics is close to the linear one and divides into two regions for quasi-inphase and quasi-antiphase oscillations. But for the large level of the excitation after the definite value of $N=N_{b}$ in the bifurcation way the region of another dynamics appears. For $N>N_{b}$ the minimum of the energy corresponds to the essentially nonlinear regime with nonunifor average distribution of the energy between two oscillators. At the same time the critical point which correspond to the in-phase oscillations transforms into saddle one and in-phase regime becomes unstable. As integrable the studied systems allow the solutions in the quadratures. The exact solution of the dynamical equations for nonlinear dynamics were obtained and analysed. The main result consists in the above prediction of the nonuniform states with different energies of subsystems, their stability and instability of inphase oscillations. The nonuniform states corresponds to the solitonic excitations in the systems with distributed parameters.

Keywords: dynamical systems, excitations, integrability, integrals of motion, phase portrait, critical points, bifurcation, Landau-Lifshits equation, magnerization.

\author{
Динаміка зв’язаних нелінійних систем \\ О.С. Ковальов ${ }^{1,2}$, Я.С. Прилепський ${ }^{3}$, К.О. Градюшко ${ }^{2}$ \\ 1. Фізико технічний інститут низьких температур ім. Б.І. Вєркіна НАН Украӥни, пр-т Науки 47, 61103 Харків, \\ Украӥна \\ 2. Харківський національний університет імені В.Н. Каразіна, м. Свободи 4, 61022, Харків, Украӥна \\ 3. Triangle Birmingham University, Aston Triangle, Birmingham, B4 7ET, UK,
}

Теоретично розглянуто дві моделі, що описують динаміку двох нелінійних елементів з лінійною і нелінійною взаємодією між ними. Ці моделі описують, наприклад, перемикачі в нелінійних оптичних світловодах, а також штучні решітки магнітних нанодотів і магнітні шари у квазідвовимірних магнітних сполуках. Запропоновані моделі ілюструють загальну ситуацію в нелінійних системах з двома ступенями вільності. Звичайно відсутність інтеграла руху, додаткового до повної енергії, призводить до появи хаотичної компоненті руху. Ця хаотична поведінка затемнює головні характеристики регулярного руху. В розглянутих в статті двох інтегрованих системах хаотична компонента відсутня і регулярна динаміка проявляється в чистому вигляді. Спочатку в роботі динаміку системи розглянуто якісно на відповідних фазових площинах. Два інтеграла руху відповідають повній енергії $E$ і числу елементарних збуджень $N$ (фотонів і спінових відхилень) системи. Фазовий аналіз демонструє складний характер динаміки. Збудження різного типу класифікуються на площині 
інтегралів руху $(N, E)$. При фіксованому числі збуджень $N$ в області малих значень $N$ динаміка близька до динаміки лінійних систем і ця область поділяється на дві з квазі-синфазними і квазі-протифазними типами коливань. Але при великому рівні збудження після певного після значення $N=N_{b}$ біфуркаційним чином з'являється область параметрів 3 зовсім іншою динамікою. При $N>N_{b}$ мінімуму енергії відповідає суттєво нелінійний режим 3 неоднорідним середнім поділом енергії між окремими осциляторами. Одночасно особлива точка, що відповідає синфазним коливанням, перетворюється на сідлову і режим синфазних коливань стає нестійким. Як интегровні, розглянуті системи допускають розв'язки в квадратурах. Було отримано і проаналізовано точні розв'язки рівнянь нелінійної динаміки. Головний результат полягає в передбаченні неоднорідних станів з різними енергіями підсистем. Ці стани відповідають солітонним збудження в системах з розподіленими параметрами.

Ключові слова: динамічні системи, збудження, інтегрованість, інтеграли руху, фазовий портрет, особливі точки, біфуркація, рівняння Ландау-Ліфшиця, намагничення.

\author{
Динамика связаных нелинейных систем \\ А.С. Ковалёв ${ }^{1,2}$, Я.Е. Прилепский ${ }^{3}$, К.А. Градюшко ${ }^{2}$ \\ 1. Физико технический институт низких температур им. Б. Веркина НАН Украинь, пр-т Науки 47, 61103 Харьков, \\ Украина \\ 2. Харьковский национальный университ им. В.Н.Каразина, пл. Свободы 4, Харьков 61022, Украина \\ 3. Triangle Birmingham University, Aston Triangle, Birmingham, B4 7ET, UK,
}

Теоретически рассмотрены две модели, описывающие динамику двух нелинейных элементов с линейным и нелинейным взаимодействием между ними. Эти модели описывают, например, переключатели в нелинейных оптических световодах, а также искусственные решетки магнитных нанодотов и магнитные слои в квазидвумерных магнитных соединениях. Были получены и проанализированы точные решения уравнений нелинейной динамики. Основной результат состоит в предсказании неоднородных состояний с различными энергиями подсистем. Эти состояния соответствуют солитонным возбуждениям в системах с распределенными параметрами. Предложенные модели иллюстрируют общую ситуацию в нелинейных системах с двумя степенями свободы. Обычно отсутствие интеграла движения, дополнительного к полной энергии, приводит к появлению хаотической компоненты динамики. Это хаотическое поведение затеняет основные характеристики регулярного движения. В рассматриваемых в работе двух интегрируемых системах хаотическая компонента отсутствует и регулярная динамика проявляется в чистом виде. В работе вначале динамика систем рассматривается качественно на соответствующих фазовых плоскостях. Два интеграла движения соответствуют полной энергии $E$ и числу $N$ элементарных возбуждений (фотонов и спиновых отклонений) системы. Фазовый анализ демонстрирует сложный характер динамики. Возбуждения разного типа классифицируются на плоскости интегралов движения $(N, E)$. При фиксированном числе возбуждений $N$ в области малых значений $N$ динамика близка к динамике линейных систем, и эта область разделяется на две с квази-синфазным и квази-противофазным видами колебаний. Но при большом уровне возбуждения после определенного значения $N=N_{b}$ бифуркационным образом появляется область параметров с совершенной другой динамикой. При $N>N_{b}$ минимуму энергии соответствует существенно нелинейный режим с неоднородным средним распределением энергии между отдельными осцилляторами. Одновременно особая точка, соответствующая синфазным колебаниям превращается в седловую точку и режим синфазных колебаний становится неустойчивым. Будучи интегрируемыми, рассмотренные системы допускают решения в квадратурах. Были получены и проанализированы точные решения уравнений нелинейной динамики. Основной результат состоит в предсказании неоднородных состояний с различными энергиями подсистем. Эти состояния соответствуют солитонным возбуждениям в системах с распределенными параметрами.

Ключевые слова: динамические системы, возбуждения, интегрируемость, интегралы движения, фазовый портрет, особые точки, бифуркация, уравнение Ландау-Лифшица, намагниченность.

Although the non-linear dynamics of dynamical systems is a traditional field of physics, the last halfcentury exhibits its essential progress, related to the active study of soliton excitations and their manifestations in the physics of condensed matter. Recently a particular interest is connected with the study of non-linear discrete systems linking the areas of nonlinear oscillations and nonlinear waves. Under a weak localization of non-linear excitations in discrete systems, the whole non-linear dynamics is localized on several elements of the lattice. Recently, this problem has become more actual due to the active research and application in nano-objects such as the coupled effective spin torque oscillators [1], the cavities containing SQUIDs with Josephson junctions connections as the equipment for the quantum computer [2], high-gain weakly nonlinear flax-modulated Josephson parametric 
amplifier using a SQUID arrays [3,4], coupled micromechanical resonators [5], microelectromechanic (MEM) coupled cantilevers and nunoelectromechanical (NEM) systems [6], magnetic bilayers with F/N/F structures [7], bicomponent magnonic crystals [8], arrays of optical waveguides, optical switch and coupled modes in nonlinear optical waveguides [9]. As it was first demonstrated in [10,11], many elements of solitary physics in systems with distributed parameters have their analogous in systems with the final number of degrees of freedom, particularly in systems with two elements [12]. Unfortunately, in hamiltonian systems with two degrees of freedom, in the absence of additional integral of motion, there appears a chaotic component of dynamics, which defaces such an important element of motion as the localization of excitations on one degree of freedom. In its evident form, this phenomenon manifests itself in integrable systems with two degrees of freedom. Some examples of such systems are discussed in this article. As a first example, consider two bounded elements of the socalled DSTM (discrete self trapping model). It describes, for example, a system of two closely connected optical fibers or two weak coupled magnetic nanodots.

\section{DSTM for two coupled non-linear elements.}

It is convenient to describe the dynamics of a linear oscillator in terms of complex quantity $\psi=\left(\omega_{0} x+i p / m\right) / \sqrt{2 \omega_{0}}$, which plays the role of a classic analogue of the annihilation operator for the quantum of the excitation of oscillator with frequency $\omega_{0}$

. By taking into account the weak (Linear) interaction between oscillators and the simplest form of self nonlinearity (of on-site potential), we get for the two oscillators in a resonant approximation the system of two equations:

$$
i \dot{\psi}_{n}=\omega_{0} \psi_{n}-\alpha\left|\psi_{n}\right|^{2} \psi_{n}+\varepsilon\left(\psi_{n}-\psi_{m}\right)
$$

where $n, m=1,2$. The system of equations (1) is the integrable one, with two integrals of motion: full energy

$$
E=\sum\left(\omega_{0}\left|\psi_{n}\right|^{2}-\alpha\left|\psi_{n}\right|^{4} / 2\right)+\varepsilon\left|\psi_{1}-\psi_{2}\right|^{2}
$$

and additional integral

$$
N=\sum\left|\psi_{n}\right|^{2},
$$

coincided with the adiabatic invariant and represented the number of excitations under the quasi-classical interpretation of the dynamics of the coupled oscillators.
Whereas $N=$ const, it's convenient to introduce the following new variables

$$
\begin{aligned}
& \psi_{1}=\sqrt{N} \cos \vartheta \exp \left(i \phi_{1}\right), \\
& \psi_{2}=\sqrt{N} \sin \vartheta \exp \left(i \phi_{2}\right),
\end{aligned}
$$

in terms of which equations (1) will be rewritten as

$$
\begin{gathered}
\dot{u}=2 \varepsilon \sin \psi, \\
\dot{\psi}=2 \varepsilon \operatorname{ctg}(u) \cos \psi-\alpha N \cos (u),
\end{gathered}
$$

where $u=2 \vartheta$ and $\psi=\phi_{2}-\phi_{1}$. This closed system for the variables $u$ and $\psi$ is supplemented by the equation for the variable $\phi=\phi_{2}+\phi_{1}$ :

$$
\dot{\phi}=-2\left(\omega_{0}+\varepsilon-\alpha N / 2\right)+2 \varepsilon \cos \psi / \sin (u)
$$

In new variables the energy reeds as

$$
\begin{aligned}
& E=\left(\omega_{0}+\varepsilon(1-\sin (u) \cos \psi)\right) N- \\
& -\alpha\left(1+\cos ^{2}(u)\right) N^{2} / 4
\end{aligned} .
$$

Equations (1) allow single-frequency solutions corresponding to stationary states with the following relation between the amplitudes of oscillators:

$$
\left(a_{1}-a_{2}\right)\left(a_{1}+a_{2}\right)\left(a_{1} a_{2}-\varepsilon / \alpha\right)=0 \text {. }
$$

Thus the in-phase (s), anti-phase (a) and nonuniform (n) stationary states with the following dependencies of frequency oscillations on the solution norm are possible

$$
\begin{gathered}
\omega_{s}=\omega_{0}-\alpha N / 2, \quad \omega_{s}=\omega_{0}-\alpha N / 2, \\
\omega_{a}=\omega_{0}+2 \varepsilon-\alpha N / 2, a_{2}=-a_{1} a_{2}=-a_{1}, \\
\omega_{n}=\omega_{0}+\varepsilon-\alpha N, \quad a_{2}=\varepsilon a_{1} / \alpha .
\end{gathered}
$$

These dependencies demonstrate two important properties of non-linear oscillations: the dependence of the frequency of oscillations on their energy (or, what is the same - on their norm), and the appearance in bifurcation way at the critical level of the excitation $N>N_{b}=2 \varepsilon / \alpha$ of the new type of motion with different amplitudes of oscillations for the different 
elements of the system $a_{1} \neq a_{2}$, i.e. the localization of energy on one of the oscillators. These features of the dynamics are illustrated in Fig. 1a. Unfortunately, only the single-frequency solutions can be depicted on the plane $(\omega, N)$, while the vibrations of the general type are two-frequency with incommensurate frequencies. Their properties are convenient to discuss on the plane of the integrals of motion $(E, N)$.

The dependences of the energy of single-frequency oscillations on their norms (adiabatic invariants) is determined by the usual mechanical ratio $\omega=d E / d N$. Therefore, it is easy to get the relation between the motion integrals for single-frequency vibrations, corresponding to dependencies (9-11):

$$
\begin{gathered}
E_{s}=\omega_{0} N-\alpha N^{2} / 4, \\
E_{a}=\left(\omega_{0}+2 \varepsilon\right) N-\alpha N^{2} / 4, \\
E_{n}=\left(\omega_{0}+\varepsilon\right) N-\alpha N^{2} / 2-\varepsilon^{2} / \alpha, \\
E_{*}=\left(\omega_{0}+\varepsilon\right) N-\alpha N^{2} / 2, \\
\tilde{E}=\left(\omega_{0}+\varepsilon\right) N-\alpha N^{2} / 4-2 \varepsilon^{2} / \alpha .
\end{gathered}
$$

Here the important (as it will be seen below) dependences $(15,16)$ are given in which there appear the significant changes in the dynamics of the system). The dependencies (12-16) are depicted on Fig.1b.

On Fig. 1b, the line (a) corresponds to anti-phase oscillations (phases of which differ on $\pi$ ), line (s) $\left(0 b b^{\prime} s E_{s}\right)$ - to in-phase oscillations, line $(\mathrm{n})-\left(b n E_{n}\right)-$ to localized states with different levels of excitation of the oscillators (localization of energy on one element of the system), and line $\left(0 b^{\prime} E_{*}\right)$ corresponds to the dependency from Eq.(14). Equations $(5,6)$ correspond to the effective system with one degree of freedom and the integration of motion (7), which can be integrated in quadratures, and its dynamics is depicted on the "phase plane" $(u, \psi)-$ Fig.2.

On Fig. 2a, the special points such as "center" (s) and (a) correspond to single-frequency in-phase and antiphase oscillations and to the lines (Ob) and (0a) in Fig.1b, while the detached separatrix (C) separates the oscillations close to the in-phase one from those close to the anti-phase oscillations. It corresponds to the dependence (14) and to the line $\left(0 b^{\prime}\right)$ in Fig. $1 \mathrm{~b}$.
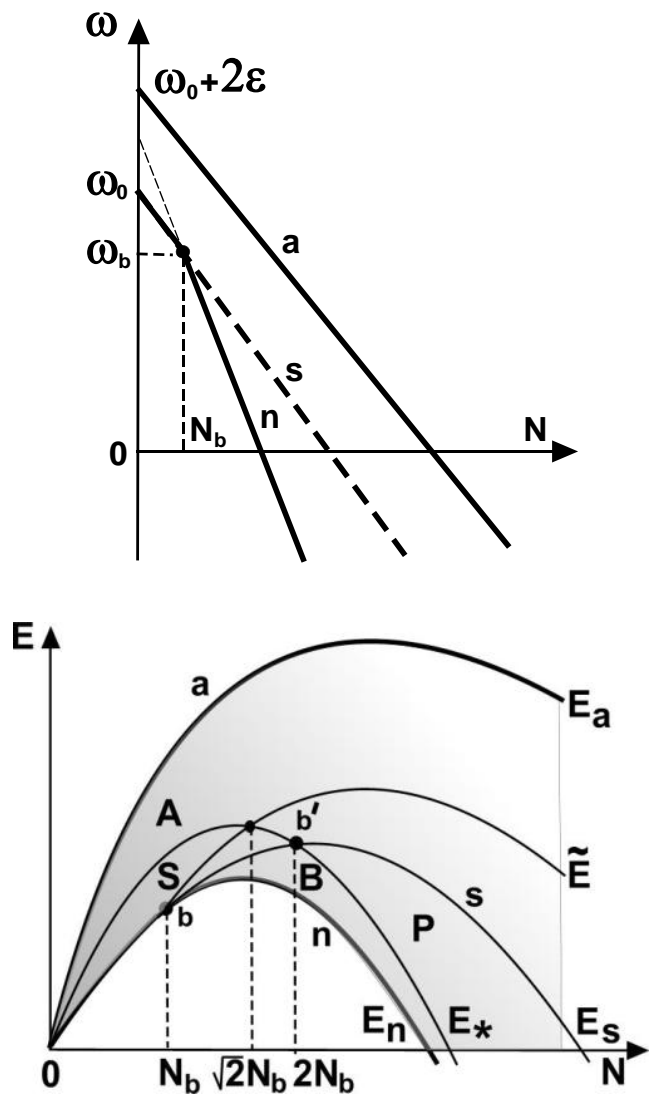

(a)

Fig. 1. Dependences of the stationary state frequencies on the norms of the solutions (a) and (b) - the area of existence of solutions with different dynamics on the plane $(E, N)$ of integrals of motion.of integrals of motion.

Special points of the type of "centeres" are stable, which indicates the stability of in-phase and anti-phase excitations in this interval of the values of norm. At the point of bifurcation (b) there appear two new states with different values of oscillators excitations: two new centers in Fig.2b. They correspond to the line (n) in Fig.1a and the line $\left(b n E_{n}\right)$ in Fig.1b. The saddle point $(u=\psi=0)$ is now associated with in-phase oscillations. This denotes that the in-phase oscillations become unstable while $N>N_{b}$. They correspond to the dashed line (s) in Fig.1a and the line $\left(b b^{\prime} s E_{s}\right)$ in Fig.1b. The last line simultaneously corresponds to the separate loops S in Fig/ 2b. The areas inside the separatrix $S$, between the separatrices $S$ and $C$ and outside of them, correspond respectively to the domains $B, S$ and $A$ in Fig.1b. The second bifurcation takes place at $N=2 N_{b}$, i.e. in the point of merging of separatices $S$ and $C$ on the phase portrait (triangles in Fig.2c). Finally, at $N>2 N_{b}$ the two 
separatrices are separated again (Fig..2d), but the separatrix which going out of the saddle point of the inphase oscillations does not have a form of closed separation loop.

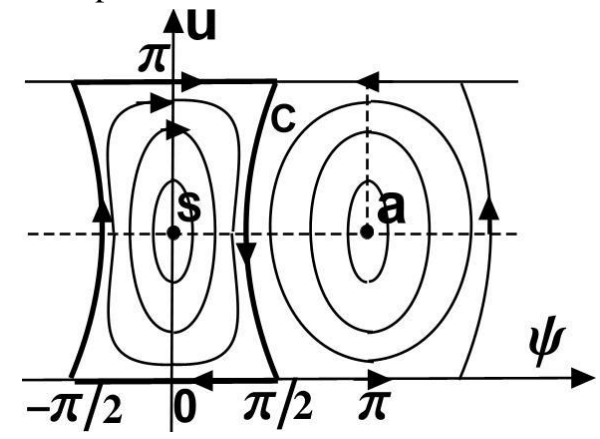

(a)
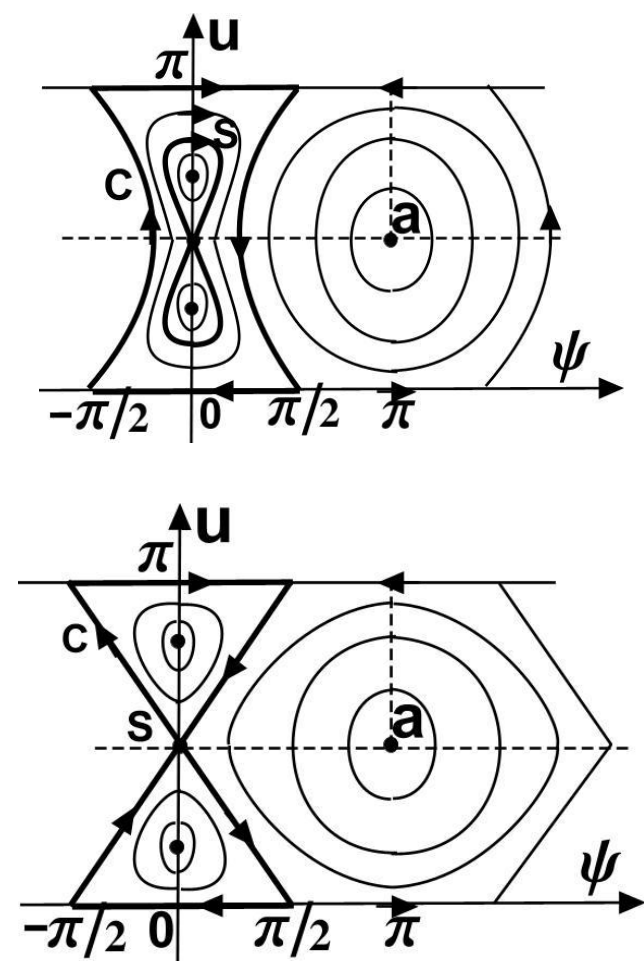

(b)

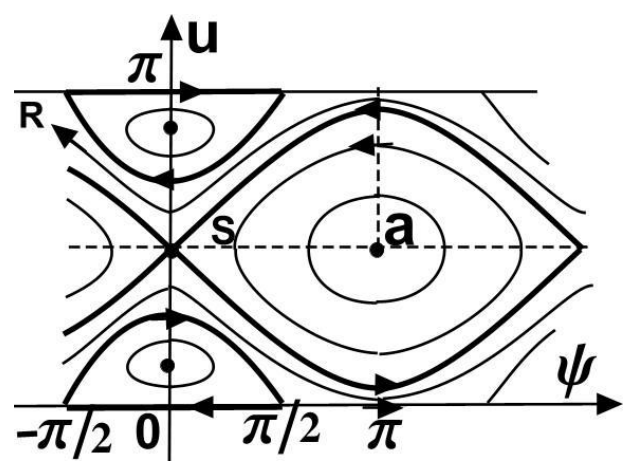

(c)

(d)

Fig. 2. Phase portraits of the system $(5,6)$ on the plane of variables $(u, \psi)$ at different values of the complete norm of the solution: $N<N_{b}$ (a), $N_{b}<N<2 N_{b}$ (b), $N=2 N_{b}$ (c) and $N>2 N_{b}(\mathrm{~d})$.
The states studied in the phase plane allow exact analytical solutions. From Eq. (7) it results the relation $\psi=\psi(u, E, N)$ :

$$
\cos \psi=\frac{\left(E_{*}-E\right)+\left(\alpha N^{2} / 4\right) \sin ^{2} u}{\varepsilon N \sin (u)},
$$

and for the new variable $f=(\sqrt{\alpha} N / 2) \cos (u)$ Eq. (5) can be reduced to a closed equation for the function $f$ :

$$
\dot{f}^{2} / \alpha=\left(A_{1}-f^{2}\right)\left(f^{2}-A_{2}\right)
$$

where

$$
A_{1,2}=\left((\tilde{E}-E) \pm \frac{2 \varepsilon}{\sqrt{\alpha}} \sqrt{E-E_{n}}\right)
$$

1. In the domain with small level of excitation with $N<N_{b}$, in which $\tilde{E}<E_{n}<E_{s}<E<E_{a}$ (Fig. 2a),

$$
\begin{gathered}
A_{1}=-(E-\tilde{E})+\frac{2 \varepsilon}{\sqrt{\alpha}} \sqrt{E-E_{n}}=a^{2}<b^{2}, \\
A_{2}=-(E-\tilde{E})-\frac{2 \varepsilon}{\sqrt{\alpha}} \sqrt{E-E_{n}}=-b^{2}
\end{gathered}
$$

and the solution to the equation (18) reads

$$
f=a c n\left(\sqrt{a^{2}+b^{2}} \sqrt{\alpha} t, k\right), \quad k=\frac{a}{\sqrt{a^{2}+b^{2}}},
$$

where $c n(z, k)$ denotes Jacobi's elliptical cosine. For $E=E_{a}$ we have: $a=0, b^{2}=2 \varepsilon\left(N+N_{b}\right)$ and $a=0$, $b^{2}=2 \varepsilon\left(N_{b}-N\right)$ for $E=E_{s}$. The frequency of the relative amplitude of oscillations of subsystems is equal to

$$
\Omega(E, N)=\frac{\pi \sqrt{\alpha}}{2 k K(k)} a,
$$

where $K(k)$ is the complete elliptical integral of the first kind. On the boundaries for the area of the solution existing ((a) and (s) in Fig.1b) $k \rightarrow 0, a \rightarrow 0$ and $b_{s, a} \rightarrow \sqrt{\alpha N_{b}\left(N_{b} \mp N\right)}$. That is, the frequency of periodic energy transfer between the oscillators is equal to 


$$
\Omega_{s, a}=\alpha \sqrt{N_{b}\left(N_{b} \mp N\right)}=2 \varepsilon \sqrt{1 \mp N / N_{b}} .
$$

In the linear limit, one gets the well-known result $\Omega=2 \varepsilon$. The elliptical integral module reaches the maximum value $k_{m}=N / 2 N_{b}$ on the line $E=E_{*}(N)$ (15) on which $a_{m}^{2}=\alpha N^{2} / 4$. This line corresponds to the separatrix $C$ in the phase portrait in Fig.2a.

The formula (24) describes the relative oscillations of the amplitudes of the two oscillators and they are determined by the interaction of subsystems. In addition, the system demonstrates a common "rotation" (similar to the joint rotation of two related magnetic moments) with frequencies close to the oscillators' own frequency $\omega_{0}$. This movement resembles the oscillations of two bound linear oscillators, which vibrate with the frequencies of their own modes (in-phase and anti-phase) and simultaneously demonstrate the wobbling with the frequency of the order of the magnitude of the interaction between them. In this case, there is also the transfer of energy between oscillators with frequency (24), but now the principle of superposition and normal nodes do not exist. The complete dynamics of the system is described by the following formulas:

$$
\psi_{1,2}=\sqrt{\frac{N}{2}} \sqrt{1 \pm \cos ^{2} u} \exp \left(\frac{i}{2} \int \dot{\phi} d t \mp \frac{i}{2} \int \dot{\psi} d t\right),
$$

in which the values $\dot{\psi}$ and $\dot{\phi}$ are defined by Eq. $(6,7)$. The azimuthal rotation of oscillators is determined by the exponential indicators and is expressed through the elliptical integrals of the third kind. This movement consists of average rotation with frequency $v=\langle\dot{\phi} \mp \dot{\psi}\rangle / 2$, where angular brackets mean the averaging over the period, and additional azimuthal oscillation with frequency $\Omega$.

Integral in expression (25) also gives an additional linear in time contribution, and the total formula in the limits $E \rightarrow E_{s}$ and $E \rightarrow E_{a}$ leads to synchronous inphase and anti-phase rotations with frequencies $(9,10)$. The amplitude of modulation for the excitations of individual oscillators is equal to $\delta N=4 a^{2} / \alpha N$, and on the line $E=E_{*}(N)$ we have $\delta N_{\max }=N$, i.e. the periodic full pumping of energy between oscillators is observed.

Thus, in the system of coupled anharmonic oscillators, the movement is two-frequency, but it does not represent the overlay of normal modes: the frequency of energy exchanging between oscillators (radial movement) does not represent a difference between the frequencies of azimuth rotations (main non-linear oscillations).

2. In the domain of large excitations with $N_{b}<N<2 N_{b}$, where $E_{n}<E_{s}<\tilde{E}<E_{a}$ (Fig.2b), we have

$$
\begin{gathered}
A_{1}=-(E-\tilde{E})+\frac{2 \varepsilon}{\sqrt{\alpha}} \sqrt{E-E_{n}}=a^{2}, E_{n}<E<E_{a}, \\
A_{2}=-(E-\tilde{E})-\frac{2 \varepsilon}{\sqrt{\alpha}} \sqrt{E-E_{n}}=-b^{2}, E_{s}<E<E_{a}, \\
A_{2}=-(E-\tilde{E})-\frac{2 \varepsilon}{\sqrt{\alpha}} \sqrt{E-E_{n}}=c^{2}<a^{2}, \\
E_{n}<E<E_{s} .
\end{gathered}
$$

Thus, the area for the acceptable values of parameters $N$ and $E$ is divided into two parts with $E>E_{s}$ and $E<E_{s}$. (The domain (27) corresponds to (A) in Fig.1b). From the same picture one can see that now the dependence $\tilde{E}(N)$ is inside the domain (A), and while passing through over the parameters $(E, N)$ the solution slightly changes: at $\tilde{E}<E<E_{a}$ as in previous case $a^{2}<b^{2}$, and when $E_{s}<E<\tilde{E}$ we have $a^{2}>b^{2}$. For $a^{2}>b^{2}$ in this area at the border $E=E_{s}$ parameters $b=0$ and $a^{2}=2 \varepsilon\left(N-N_{b}\right)$. Thus, on the border $E=E_{s}$ corresponding to the separatrix $S$ in Fig.2b, the module $k=1$ and the solution is aperiodical:

$$
\cos u=\frac{2 \sqrt{N_{b}\left(N-N_{b}\right)}}{N} \operatorname{cosech}\left(\sqrt{\frac{N-N_{b}}{N_{b}}} 2 \alpha t\right) .
$$

(The line $E=\tilde{E}$ still corresponds to the separatrix $C$ in Fig.1b). In the region $E_{n}<E<E_{s}$ the solution is radically modified:

$$
f=a d n(a \sqrt{\alpha} t, k), \quad k=\frac{\sqrt{a^{2}-c^{2}}}{a} .
$$

At the border $E=E_{s}$ the parameters of the solution are equal to $a^{2}=2 \varepsilon\left(N-N_{b}\right), c=0$ and $k=1$. On the other border $E=E_{n}$ they take the values $a^{2}=c^{2}=\alpha\left(N^{2}-N_{b}^{2}\right) / 4$ and $k=0$. Modulation of the 
levels of excitations of two oscillators is determined by the expression

$$
N_{1,2}=\frac{N}{2} \pm \frac{a}{\sqrt{\alpha}} d n(a \sqrt{\alpha} t, k) \text {. }
$$

It is important that although in this area of the system parameters $N>N_{b}$ and $E_{n}<E<E_{s}$, as above, there is the periodic exchange of energy between oscillators with the frequency

$$
\Omega=\frac{\pi \sqrt{\alpha}}{K(k)} a(E, N),
$$

but now the average level of the excitations of individual subsystems is not equal:

$$
\left\langle N_{1,2}\right\rangle=N(1 \pm \pi a / \sqrt{\alpha} N K) / 2 \text {. }
$$

At the border of the area for the existence of solutions with the maximum difference of the excitations of oscillators we have $\left\langle N_{1,2}\right\rangle=N\left(1 \pm \sqrt{1-N_{b}^{2} / N^{2}}\right) / 2$. In the limit $N \rightarrow \infty$ the total energy is concentrated on one of the oscillators: $\left\langle N_{1}\right\rangle \rightarrow N,\left\langle N_{2} \rightarrow 0\right\rangle$. Such the spatial localization of energy in the system of identical oscillators is the nature of the solitary localization in non-linear systems with distributed parameters.

From Fig.2 it is clear that the purely in-phase oscillations correspond to a special point of the "saddle" point. Therefore the in-phase oscillations become unstable (see dotted line in Fig.1a). From this point separatrix loops "come out", which correspond to the aperiodic evolution for the amplitudes of oscillators. (But they are accompanied by periodic in-phase rotation of oscillators with a large frequency of order of $\omega_{0}$ ). The specific type of separatrices depends on the norm of the solution $N$. While $N_{b}<N<2 N_{b}$ two separatrices $S$ and $C$ in Fig.2b ( $E_{*}$ and $E_{s}$ in Fig.1b) separate quasi-in-phase and quasi-anti-phase oscillations and quasi-in-phase and heterogeneous oscillations, respectively. For $N=2 N_{b}$ (Fig.2c) these separtricec merge and the aperiodic component of the movement looks particularly simple: $u=\pi / 2 \pm \psi$ and $N_{1}=N / 2 c h^{2}(2 \varepsilon t)$. Oscillators rotate with frequency $\Omega=\omega_{0}-\varepsilon$ and with the total phase shift equal to $\pi$. This phase shift is also preserved at $N>2 N_{b}$ for one of the separatrices ( $E_{*}$ on Fig.1b).

\section{The dynamics of the two interaction magnetic moments.}

The linearly interacting anharmonic systems were considered above. Another object of study is non-linearly interacting dynamic systems. An the example is two bounded classical magnetic moments (interacting magnetic nanodots, magnetic layers or two interacting magnetic sublattices). In particular case, such a system describes the spatially homogeneous excitations in antiferromagnets. Let's restrict ourselves with the case of the easy-type magnetic anisotropy, in which the classical magnetic moments of the two subsystems $\vec{M}_{1}$ and $\vec{M}_{2}$ at ground state are oriented along the so-called "easy axis" ( $Z$-axis). The total energy of such a system reads [13]:

$$
E=-J \vec{m}_{1} \vec{m}_{2}-(\beta / 2) \sum m_{i z}^{2}+J+\beta
$$

where $\vec{m}_{i}=\vec{M}_{i} / M_{0}$-normalized magnetic moment, $\beta=\omega_{0}$ - the constant of single-ion anisotropy (frequency of homogeneous ferromagnetic resonance), $J$-the constant of exchange interaction (below $J=\varepsilon$ ), which is positive for ferromagnetic case and negative for antiferromagnetic. (While choosing the energy in the form (34) the ground state of a "ferromagnetic" type has zero energy). In the classical approach, the dynamics of the magnetic system can be described in the framework of a discrete analogue of the Landau-Lifshitz equation [14]: $d \vec{m}_{j} / d t=\left[\bar{m}_{j} \times \partial E / \partial \vec{m}_{j}\right] . \quad$ In components $\psi_{i}=m_{i x}+i m_{i z}$ and $m_{i}=m_{i z}$ they have the form:

$$
i d \psi_{i} / d t=\omega_{0} \psi_{i} m_{i}+\varepsilon\left(\psi_{i} m_{j}-\psi_{j} m_{i}\right)
$$

have the same structure as the equations (1) and transform into them in linear limit.

For the description of the magnetic moments it is convenient to use the polar coordinate system in which $\psi_{i}=\sin \vartheta_{i} \exp \left(i \phi_{i}\right)$. Then the system of two complex equations (35) is reduced to a system of three first-order real equations for $\vartheta_{i}$ and $\psi=\phi_{2}-\phi_{1}$ :

$$
\begin{gathered}
d \vartheta_{1} d t=2 \varepsilon \sin \vartheta_{2} \sin \psi, \\
d \vartheta_{2} d t=-2 \varepsilon \sin \vartheta_{1} \sin \psi,
\end{gathered}
$$

$$
\begin{aligned}
& d \psi / d t=\left(2 \varepsilon-\omega_{0}\right)\left(\cos \vartheta_{1}-\cos \vartheta_{2}\right)-2 \varepsilon \cos \psi^{*} \\
& *\left(\sin ^{2} \vartheta_{1} \cos \vartheta_{2}-\sin ^{2} \vartheta_{2} \cos \vartheta_{1}\right) / \sin \vartheta_{1} \sin \vartheta_{2}
\end{aligned}
$$


In addition to the total energy (34), the system under consideration has the additional integral of motion - a complete projection of magnetization $M=\sum \cos \vartheta_{i}$ onto the easy axes. This integral is similar to the total norm in the previous example, and the total number of spin deviations $2-M=N$ plays the role of the number of elementary excitations while the quasi-classical quantization. Unlike the previous case, the number $N$ is now limited by the value: $0<N<2$. (The value 2 corresponds to the configuration in which both the moments are perpendicular to the easy axis). The presence of two motion integrals leads to the complete integrability of the system under consideration and the possibility of obtaining its solution in the quadratures. The difficulty of the problem is connected with the choosing of the convenient variables which takes into account the presence of one of the motion integrals $(N)$. Let us introduce instead of two variables $\vartheta_{i}$, one variable $P$, such that $\cos \vartheta_{i}=M / 2 \pm(1-M / 2) P$, and the condition of the conserving for the total magnetization is fulfills automatically. Finding from the expression for the energy

$$
\begin{aligned}
& E=\omega_{0}\left(\sin ^{2} \vartheta_{1}+\sin ^{2} \vartheta_{2}\right) / 2- \\
& -\varepsilon\left(\cos \vartheta_{1} \cos \vartheta_{2}+\sin \vartheta_{1} \sin \vartheta_{2} \cos \psi\right)+\varepsilon
\end{aligned}
$$

the connection $\psi=\psi\left(\vartheta_{i}, E\right)$ and substituting it in (36), we obtain the closed equation for the value $P$ :

$$
(d P / d t)^{2}=-A-B P^{2}-C P^{4},
$$

where

$$
\begin{gathered}
A=4\left(E-\omega_{0}\left(1-M^{2} / 4\right)\right) * \\
*\left[E-\left(\omega_{0}+2 \varepsilon\right)\left(1-M^{2} / 4\right)\right] /(1-M / 2)^{2}, \\
B=8\left(\left(\omega_{0}-\varepsilon\right) E-\omega_{0}^{2}\left(1-M^{2} / 4\right)+2 \varepsilon^{2}\right), \\
C=4 \omega_{0}\left(\omega_{0}-2 \varepsilon\right)(1-M / 2)^{2} .
\end{gathered}
$$

Solutions of the equation (40-43) can be represented in terms of elliptical Jacoby functions, but at first we research the obtained system qualitatively. It allows the single-frequency states (stationary states) which describe the synchronous pure rotations of two magnetization vectors: $\psi_{i}=a_{i} \exp (-i \omega t)$. As in the previous example, rotations are accepted with phases which differ in $\pi$ (anti-phases-(a)) and with the same phases: with the same amplitudes (in-phase -(s)) and different amplitudes (nonuniform ones-(n)). Nonuniform states exist only when inequality $\varepsilon<\omega_{0} / 2$ is valid. (In real magnets, the exchange interaction is essentially large then the energy of magnetic anisotropy $(J>>\beta)$, but in layered quasitwo-dimensional magnets and nanodots systems, the inequality we have used can be performed). The amplitudes of the rotations of the moments are linked by the relation:

$$
\left(m_{1}-m_{2}\right)\left(\left(\omega_{0}-\varepsilon\right) a_{1} a_{2}-\varepsilon\left(1+m_{1} m_{2}\right)\right)=0 .
$$

In in-phase and anti-phase states $m_{1}=m_{2}$ and $a_{1}= \pm a_{2}$, in the nonuniform stationary states $m_{1} m_{2}=-1+M(1-\kappa) / \sqrt{1-2 \kappa}$, where $\kappa=\varepsilon / \omega_{0}$. In stationary states, the frequencies of these excitations dependence on the number of spin deviations $N$ has the form of

$$
\begin{array}{cc}
\omega_{s}=\omega_{0}(1-N / 2), & a_{2}=a_{1}, \\
\omega_{a}=\left(\omega_{0}+2 \varepsilon\right)(1-N / 2), & a_{2}=-a_{1}, \\
\omega_{n}=\omega_{0}(M-\sqrt{1-2 \kappa}), & a_{2} \neq a_{1} .
\end{array}
$$

These dependences are shown in Fig. 3a. At the critical value of the level of excitation $N_{b}=2(1-\sqrt{1-2 \kappa})$ two dependences for the nonuniform rotations $(n)$ split from the line of in-phase rotations.

Corresponding dependencies of energy on the norm for the three types of stationary rotations of magnetic moments have the form:

$$
\begin{gathered}
E_{s}=\omega_{0} N-\omega_{0} N^{2} / 4, \\
E_{a}=\left(\omega_{0}+2 \varepsilon\right)\left(N-N^{2} / 4\right), \\
E_{n}=\left(\omega_{0}+2 \varepsilon\right) / 2-\omega_{0}(M-\sqrt{1-2 \kappa})^{2} / 2, \\
E_{q}=\left(\omega_{0}^{2}\left(N-N^{2} / 4\right)+2 \varepsilon^{2}\right) /\left(\omega_{0}-\varepsilon\right) .
\end{gathered}
$$

These dependencies are represented in Fig.3b. (On the line $E_{q}=E_{q}(N)((5)$ and $(q)$ in Fig.3b) the value $B$ in (42) changes the signs). The domain $N>2$ corresponds to the similar excitations above another ground state with 
$M=-2$. In the limit $N \rightarrow 2(M \rightarrow 0)$, the frequency of in-phase and anti-phase rotations of magnetization tends to zero and It appears the static configurations with collenear and anti-collinear configurations of magnetization vectors in the "heavy" plane.
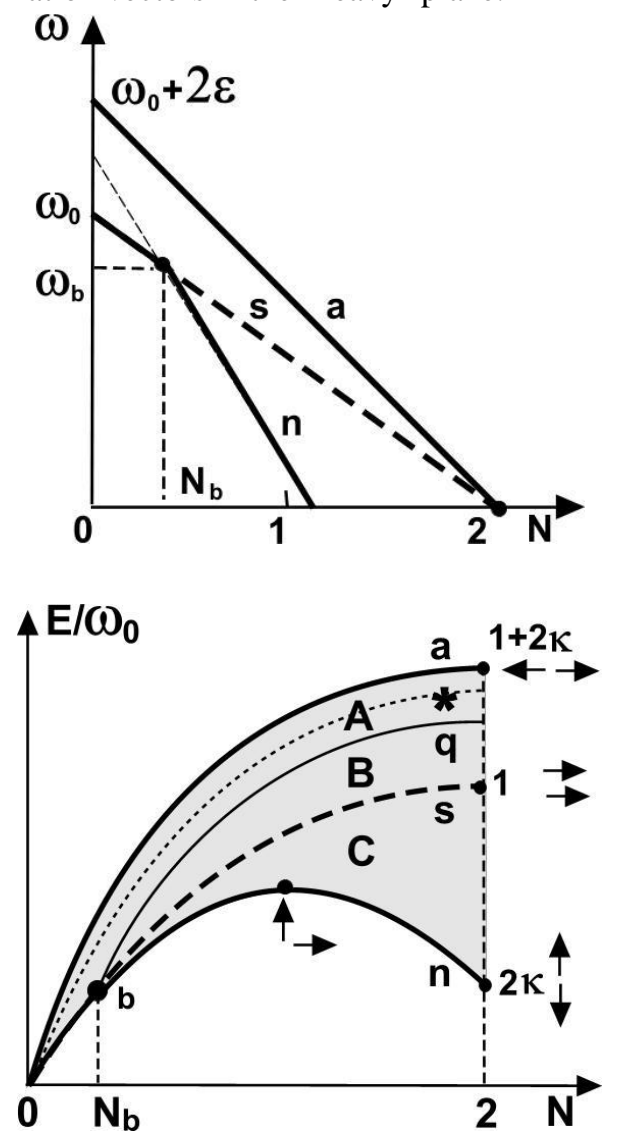

(a)

(b)

Fig. 3. The dependences of stationary state frequencies on the number of spin deviations (a) and (b) - the domains of the existence for the solutions with different dynamics subject to the values of motion integrals $(E, N)$

The nonuniform state in this limit represents the anticollinear configuration with moments along the easy axis with precession frequency $\omega=\omega_{0} \sqrt{1-2 \kappa}$. The frequency of inhomogeneous excitations turns to zero at $N_{*}=2-\sqrt{1-2 \kappa}$. In this case, the vectors of two moments are orthogonal as it shown in Fig. 3 b.

The expression (41) can be represented in the following form: $A=4\left(E-E_{s}\right)\left(E-E_{a}\right) /(1-M / 2)^{2}$. Therefore the value $A$ is negative in the area of the parameters between the lines $(a)$ and $(s)$ in Fig.3b and is positive in the area between $(s)$ and $(n)$. Constant $C$ is positive in the whole domain of the acceptable parameters of the solutions. At last, $B>0$ for
$E_{q}<E<E_{a}$ and $B<0$ for $E_{n}<E<E_{q}$. So the phase portrait of the system in the "phase plane" $(P, \dot{P})$ has different structure for $N>N_{b}$ and $N<N_{b}$, and for $E_{q}<E<E_{a}$ and $E_{n}<E<E_{q}$ in the domain $N>N_{b}$ (see Fig.4). In the previous model it was possible to draw all phase trajectories in the same figure. Now we are able to represent all trajectories only in two figures for the oscillations close to in-phase one and to anti-phase. These two types of orbits are separated by phase trajectory with the largest size which correspond to the line $E_{*}(N)$ in Fig.3b with

$$
E_{*}=2\left(\omega_{0}+\varepsilon\right)\left(N-N^{2} / 4\right)
$$

The phase portrait of the system for $N<N_{b}$ is demonstrated in Fig.4a. It is similar to the portrait for linear system. The two maximal orbits in two parts of the figure are the same and correspond to the value $E=E_{*}$. This figure is the analogues to the Fig.2a and the line with $E=E_{*}$ is the same as separatrix $C$.

In the region $N>N_{b}$ the phase portrait is more complicated. The separatrix $E_{s}$ "begins" and "ends" in unstable saddle point for in-phase oscillations $(P=0, \dot{P}=0)$ and separates the domain with the nonuniform rotations of two moments. Two stable “center"-type critical points with $E=E_{n}$ correspond to the states in which only one from two moments oscillate.

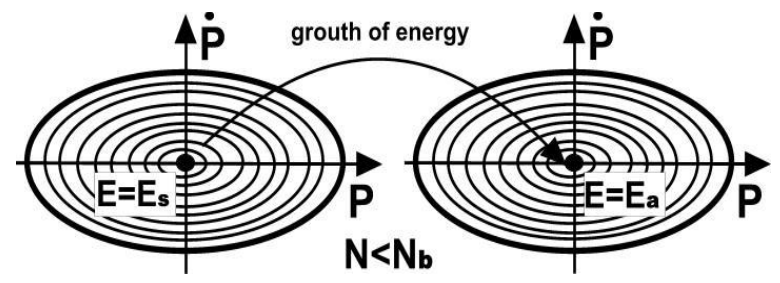

(a)

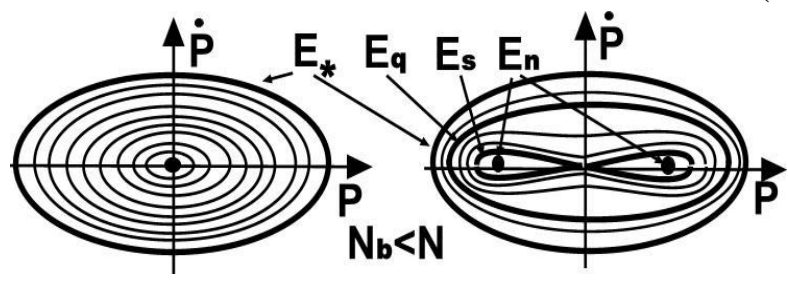

Fig. 4. Phase portraits of two coupled moments for $N<N_{b}$ (a) and $N>N$, (b).

In all the area on the outside of the separatrix $E_{s}$ (upper in energy from the line (s) in Fig.3b) the exact 
solution of Eq.(40) has the form similar to the solution (22) in previous model:

$$
P=a c n\left(\sqrt{a^{2}+b^{2}} \sqrt{C} t, k\right), \quad k=\frac{a}{\sqrt{a^{2}+b^{2}}},
$$

but with another definition of the parameters. For $N<N_{b}$ and for $N>N_{b}$ in the domain $E_{q}<E<E_{a}$ they are

$$
\begin{aligned}
& a^{2}=(B / 2 C)\left(\sqrt{4|A| C / B^{2}+1}-1\right), \\
& b^{2}=(B / 2 C)\left(\sqrt{4|A| C / B^{2}+1}+1\right) .
\end{aligned}
$$

For the small levels of excitations $N<N_{b}$ at the borders of area for the solutions $E=E_{a}, E_{s}$ parameter $A$ tends to zero and $a \rightarrow 0$ with $k \rightarrow 0$. So the function (53) transforms into trigonometrical one. The solution (53-55) describes the relative oscillations of two magnetic moments with the frequency $\Omega=\pi a \sqrt{C} / 2 k K(k)$. As above these oscillations are accompanied by the common rotation of all the system with the frequency close to the resonant frequency $\omega_{0}$ for small exchange interaction.

At $N>N_{b}$ the solution (53) preserves its form for energies $E_{s}<E<E_{q}$ but with another definition of the parameters:

$$
\begin{gathered}
a^{2}=(|B| / 2 C)\left(\sqrt{4|A| C / B^{2}+1}+1\right), \\
b^{2}=(|B| / 2 C)\left(\sqrt{4|A| C / B^{2}+1}-1\right) .
\end{gathered}
$$

Now at the line of in-phase oscillations $E_{s}((s)$ in Fig.3b) parameter $b \rightarrow 0$ and modulus $k \rightarrow 1$ : the solution at the separatrix $E_{s}$ becomes aperiodic and one spin deviates from another passing through the easy axis.

At last in the domain of the parameters $E_{n}<E<E_{s}$ as in the previous case nonuniform distribution of energy between the two moments takes place and correspondent solution of Eq.(40) has the form (30):

$$
P=a d n(a t, k), \quad k=\frac{\sqrt{a^{2}-b^{2}}}{a},
$$

with

$$
a^{2}=(|B| / 2 C)\left(1+\sqrt{1-4 A C / B^{2}}\right),
$$

$$
b^{2}=(|B| / 2 C)\left(1-\sqrt{1-4 A C / B^{2}}\right) .
$$

In the limit $E \rightarrow E_{n}$ as it follows from (40) $B^{2}=4 A C$ and modulus $k$ is equal to zero. It follows from this that $P=a(N)$ does not depend on time and so $\vartheta_{i}=$ const : magnetic moments rotate around the direction of the easy axis as common object.

\section{Conclusions.}

We investigated the nonlinear dynamics for the integrable systems of two identical coupled nonlinear elements with linear and nonlinear interparticle interaction and pay attention to some common features of this dynamics. (1) Although the principle of the superposition is absent in nonlinear systems, nevertheless the spectrum for the integrable one contains the frequencies of two definite quasilinear modes with the periodical transfer of the energy between them. (2) The most interesting facts consists in the appearance of the additional states with at the average nonuniform distribution of the energy between the degrees of freedom. This nonuniform nonlinear mode appears in the bifurcation way at the critical value of the total energy. (3) These states can be treated as the soliton analogous in the system with the finite numbers of the degrees of freedom.

\section{References}

1. F.Johansen, J.Linder, arXiv:1606.02720v1 [cond-mat. meshall] (2016).

2. W.Wustmann, V.Shumeiko, Fizika Nizkih temperature, 45, 995(2019) [LTP, 45, 995 (2019)

3. X.Zhon, V.Schmitt, P.Bartet et al., Phys. Rev. B 89,21517 (2014).

4. M.A.Castellanos-Beltran, K.D.Irvin et al., Nature Phys., 4, 929 (2008).

5. D.K.Agrawal, J.Woodhouse, A.Sesha, Phys. Rev. Lett., 111, 084101 (2013)

6. Qingfes Chen, Liang Huang, Ying Chang Lai, Appl. Phys. Lett., 92, 241914 (2008).

7. Y.Tserkovnyak, A.Brataas, G.Bauer, B.Halpein, Rev. Mod. Phys., 77, 1375 (2005).

8. D.Giridharan, P.Sabariesan, M.Daniel, Phys. Rev. E, 94, 032222 (2016).

9. Y.Kivshar, G.Agrawal, Optical solitons, Academic Press, Amsterdam (2003), 540 pp.

10. A.A.Ovchinnikov, ZhE`TF, 57, 263 (1969).

11. G.S.Zaft, S.P.Rejfman, Pis`ma v ZhE`TF, 15, 738 (1972).

12. A.M.Kosevich, A.S.Kovalev, Vvedenie $\mathrm{v}$ nelinejnuyu fizicheskuyu mekhaniku, Naukova dumka, Kiev (1989), 300str.

13. A.I.Akhiezer, V.G.Bar`yakhtar, S.V.Peletminskij, Spinovy`e volny`, Nauka, M. (1967), 367 str.

14. L.D.Landau, E.M.Lifshicz, Sovetskij zhurnal fiziki, 8, 153 (1935). 